\title{
Curcumin Analogs, PGV-1 and CCA-1.1 Exhibit Anti-migratory Effects and Suppress MMP9 Expression on WiDr Cells
}

\author{
Febri Wulandari ${ }^{1}$, Muthi’ Ikawati ${ }^{1,2}$, Mitsunori Kirihata ${ }^{3}$, Jun-Ya Kato ${ }^{4}$, Edy Meiyanto ${ }^{1,2 *}$ \\ ${ }^{1}$ Cancer Chemoprevention Research Center, Faculty of Pharmacy, Universitas Gadjah Mada, Jl. Farmako, Sekip Utara, Yogyakarta 55281, Indonesia \\ ${ }^{2}$ Macromolecular Engineering Laboratory, Department of Pharmaceutical Chemistry, Faculty of Pharmacy, Universitas Gadjah Mada, Jl. Farmako, \\ Sekip Utara, Yogyakarta 55281, Indonesia \\ ${ }^{3}$ Research Center of Boron Neutron Capture Therapy, Research Organization for the 21st Century, Osaka Prefecture University, 1-1 Gakuen-cho, \\ Nakaku, Sakai, Osaka, 599-8531, Japan \\ ${ }^{4}$ Laboratory of Tumor Cell Biology, Nara Institute of Science and Technology, Ikoma, Nara, 630-0101, Japan \\ *Corresponding author. E-mail: edy_meiyanto@ugm.ac.id
}

Received date: Apr 16, 2021; Revised date: May 31, 2021; Accepted date: May 31, 2021

\section{Abstract}

$\mathrm{B}$ ACKGROUND: Colon cancer is still a crucial concern in the development of chemotherapeutic drugs due to the drug resistance phenomenon and various side effects to patients. One of the newest compound that show anticancer activities against several cancer cells, Chemoprevention Curcumin Analog 1 (CCA-1.1), has increasingly been explored to overcome the limitation of conventional drugs.

METHODS: We evaluated the anti-migratory effect of CCA-1.1 and Pentagamavunone-1 (PGV-1) by using WiDr colon cancer cells. The expression profiles of Tumor Protein 53 (TP53) and Matrix Metalloproteinase-9 (MMP9) in colon cancer were obtained from the UALCAN database. Survival outcomes of TP53 and MMP9 in colon cancer patients were analyzed using the Kaplan-Meier method. We used 3-[4,5-dimethylthiazol-2-yl]-2,5 diphenyl tetrazolium bromide (MTT), scratch wound healing, and gelatin zymography assays to observe the cytotoxic effect, anti-

\section{Introduction}

The newest compound of curcumin analog, named Chemoprevention Curcumin Analog-1.1 or CCA1.1 (2,5-bis-(4-hydroxy-3,5-dimethyl benzylidene)- migratory activity, and MMP9 expression, respectively, in CCA-1.1 or PGV-1-treated cells.

RESULTS: Level of MMP9 was found significantly overexpressed in the primary tumor and metastasis nodal, while TP53 mutation sample types were observed and influenced the survival outcome in colon cancer patients. CCA-1.1 and PGV-1 exhibited strong cytotoxic activity after 24 and $48 \mathrm{~h}$ treatment against WiDr cells. The migration assay demonstrated that PGV-1 and CCA-1.1 at $1 \mu \mathrm{M}$ inhibited cell migration up to $40 \%$ after $48 \mathrm{~h}$ in single and combination with doxorubicin. The MMP9 expression was significantly inhibited by $0.5 \mu \mathrm{M}$ CCA-1.1.

CONCLUSION: This study emphasizes that the antimigratory effect of CCA-1.1 is better than PGV-1 via MMP9 suppression on WiDr. Thus, CCA-1.1 is prominent to be developed as an anti-metastatic agent.

KEYWORDS: chemopreventive curcumin analog 1.1 (CCA-1.1), PGV-1, WiDr cells, anti-migration, MMP9

Indones Biomed J. 2021; 13(3): 271-80 cyclopentanol) (Figure 1), has been auspiciously synthesized and gain more attention to be deeply explored for its anticancer activities. CCA-1.1 improved steadier chemical and physical features than its parent compound, Pentagamavunon-1 (PGV-1). The cytotoxic activities of CCA-1.1 against several cancer-cell types have been 


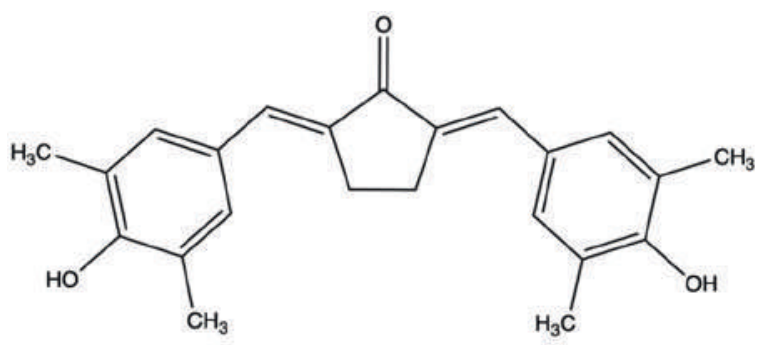

A

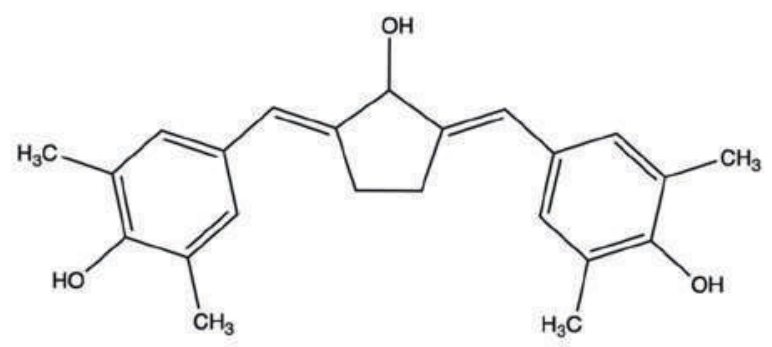

B

Figure 1. Chemical Structure of PGV-1 (2,5-bis-(4hydroxy-3,5-dimethylbenzylidene)cyclopentanone) (A) and CCA-1.1 (2,5-bis-(4hydroxy-3,5 dimethylbenzylidene)cyclopentanol) (B).

studied and performed high selectivity in non-cancerous cells. CCA-1.1 performed unique anticancer-properties differently in numerous cancer cells. $(1,2)$ The potential target of CCA-1.1 through bioinformatics studies in colon cancer have been conveyed (3), and CCA-1.1 also caused extreme intracellular reactive oxygen species (ROS) level, resulting in cell senescence and cell cycle arrest in WiDr colon cancer cells in vitro. As anti-metastasis, CCA-1.1 performs an anti-migratory effect in T47D cells, interacts with Matrix Metalloproteinase-2 (MMP2) and MMP9, and suppresses their expressions.(4) Those reported data encourage CCA-1.1 for broadened elucidate of its antimetastasis mechanism against different cancer cells.

Colon cancer continues to be a challenge in cancer research, mainly in the development of chemotherapeutic agents, due to drug resistance and numerous side effects (5), despite considerable improvements in cancer diagnostic and treatment to extend quality of life in recent (6). In this study, we intended to defeat the drawback of marketed chemotherapeutic drugs in treating cancer cells by developing a targeted anti-metastasis agent for colon cancer, since chemotherapy still the foremost choice though there remains a risk of unwanted side effects.(7) Colon cancer patients often come up with stage IV metastatic when being diagnosed, and the survival rate is less than $10 \%$, although they had given optimal supportive care.(7) As the first-line treatment option for metastatic colon cancer, 5-fluorouracil (5-FU) remains have numerous side effects such as cardiotoxicity and bone marrow suppression.(8) Cellular dysfunction and several gene mutations such as Tumor Protein 53 (TP53), Kirsten rat sarcoma viral oncogene homolog (KRAS), and adenomatous polyposis coli (APC) in colon cancer cells drive excessive cancer metastasis progression and radically disturbed these therapies. $(9,10)$.

For this purpose, PGV-1 and CCA-1.1 may be afforded the opportunity because of their lower toxic potential to be taken orally. We used WiDr cells, which contain missense-type mutant TP53 (11-13), as the model since the increasing number of TP53 mutations were detected when colon cancer has metastasized (14). The loss function of TP53 promotes the cancer cell progression and pushes forward Transforming Growth Factor beta-1 (TGF- $\beta-1$ )induced metastasis. $(9,15)$ Furthermore, CCA-1.1 described an anti-migratory activity against breast cancer-bearing TP53 mutation, T47D cells (4), and referring to PGV-1 as a potent inhibitor of WiDr (16), we assumed that PGV-1 and CCA-1.1 might also have a role in the complexity of TP53 mutation-mediated colon cancer metastasis. The antimigratory effect of lead compounds (PGV-1) $(17,18)$ can target MMP2, MMP9, Rac-1, vascular endothelial growth factor (VEGF), and other metastasis factors on breast cells also support us in believing that PGV-1 and CCA-1.1 would contribute to diminishing cell migration on colon cancer.

We continue to explore the anti-migratory effect of PGV-1 and CCA-1.1 as a candidate for anticancer involvement during cancer cell migration and MMPs expression in colon cancer cells. In this concern, we assessed the expression status of MMP9 in several types of colon cancer sample types and the predictive value from the UALCAN database.(19) We used WiDr cells treated with CCA-1.1 and PGV-1 to evaluate the MMP9 expression and the cell-migratory effects. This study supports the evidence of CCA-1.1 and PGV-1 to be developed as an anti-migratory or anti-metastatic agent for future clinical application.

\section{Methods}

\section{Data Mining of MMP9}

The MMP9 were analyzed through The Cancer Genome Atlas (TCGA) data portal using the UALCAN database. (19) The applied setting of $|\log 2 \mathrm{FC}|$ cutoff: $2, p$-value $<0.05$ 
and set to match with TCGA data. The MMP9 expression was analyzed based on specific amount (n) of TCGA sample types, including normal $(\mathrm{n}=41) v s$. primary tumor $(\mathrm{n}=286)$, nodal metastasis status ( $\mathrm{N} 0 \mathrm{n}=166$; $\mathrm{N} 1 \mathrm{n}=70 ; \mathrm{N} 2 \mathrm{n}=47$ ), and TP53 mutation status (TP53-Mutant $\mathrm{n}=160$; TP53NonMutant $\mathrm{n}=122$ ). We validated the MMP9 expression by immunohistochemistry using The Human Protein Atlas by comparing normal $v s$. tumor tissue of colon.

\section{Survival Analysis to TP53 and MMP9 Expression in Colon Cancer Patients}

Survival analysis of TP53 and MMP9 expression status in colon cancer was carried on the UALCAN website (19) according to the TCGA dataset. We analyzed the predictive value of genes $(p$-value $<0.05)$ using a Kaplan-Meier method by comparing the gene expression of colon cancer samples in transcripts per million (TPM) expression. We analyzed high vs. low expression levels of TP53 and MMP in amounts of 71 and 208, respectively.

\section{Cell Culture}

The WiDr cell line originally was obtained from Parasitology Laboratory, Faculty of Medicine, Universitas Gadjah Mada, Indonesia, and maintained by Cancer Chemoprevention Research Center (CCRC) under American Type Culture Collection (ATCC) protocol. Cells were cultured in RPMI medium (\#31800022, Gibco Life Technologies, CA, USA) complemented with fetal bovine serum (FBS) (10\% v/v) (\#10270-106, Gibco Life Technologies, CA, USA) penicillin and streptomycin $(10,000 \mathrm{units} / \mathrm{mL}$ Penicillin and $10,000 \mu \mathrm{g} / \mathrm{mL}$ streptomycin $)$ (\#15140-148, Gibco Life Technologies). The confluence cells were harvested using trypsin-EDTA (\#25200-056, Gibco Life Technologies) and re-grown in the well plate for further experiment.

\section{Cytotoxic Assay}

We used the modified MTT assay (16) to assess the cytotoxic activity. CCA-1.1 and PGV-1 were obtained from CCRC. The cells $\left(1 \times 10^{3} /\right.$ well $)$ were grown overnight in a 96-well plate (\#3599, Corning Incorporated-Life Sciences, Wujiang, Jiangsu). The next day, CCA-1.1 and PGV-1 at a concentration ranging from $0.5-20 \mu \mathrm{M}$ (4) diluted in culture medium were given 24 and $48 \mathrm{~h}$. The medium was removed and replaced with $100 \mu \mathrm{L}$ of MTT (A10079, Biobasic, Markham, ON, Canada) solution with a final concentration of $0.5 \mathrm{mg} / \mathrm{mL}$ and incubated until the formazan crystal (\#100317, Merck, Kenilworth, NJ, USA) was formed (4 h). The enzymatic reaction was stopped using SDS (\#
436163, Sigma Aldrich, St. Louis, MO, USA)-HCl (0.01 $\mathrm{N})$ and stored overnight in a dark place. The absorbances were observed using a microplate reader (Serial No. 1156, Biorad, Hercules, CA, USA) and further used for calculating the $\mathrm{IC}_{50}$ value.(21)

\section{Migration Assay}

We assessed the migratory activities of $10 \mathrm{nM}$ Dox (D1515, Sigma Aldrich) (as positive control), CCA-1.1, and PGV-1 (at the doses 0.5 and $1 \mu \mathrm{M}$ ), in single or combination with Dox in WiDr cells through the scratch wound-healing assay. $(4,22)$ The cells $\left(50 \times 10^{3} /\right.$ well $)$ were grown in a 24 -well plate (\#3820-024, Iwaki Cell Biology, Lardejero, Spain) overnight. The next day, the medium was replaced with a starvation medium $(0.5 \%$ FBS and contained $1 \mu \mathrm{g} / \mathrm{mL}$ mitomycin (\#133-15931, FUJIFILM Wako Pure Chemical Corporation, Osaka, Japan)) for $18 \mathrm{~h}$. The cells were washed with phosphate-buffered saline (PBS) (P5493, Sigma Aldrich), and a scratch was made using a sterile yellow tip for each well, followed by treatment using CCA-1.1, PGV1, Dox, or their combination. The gap closure was captured at a specific time interval using an inverted microscope and calculated as the closure percentage using ImageJ software (version 1.51).

\section{Gelatin Zymography}

The cells $\left(50 \times 10^{4} /\right.$ well $)$ were plated in a 6 -well plate $(\# 3810$ 06, Iwaki Cell Biology) overnight, then treated with the tested compounds, including $10 \mathrm{nM}$ Dox (positive control), CCA-1.1, and PGV-1 (at the doses 0.5 and $1 \mu \mathrm{M}$ ), in single or combination with Dox using the starvation medium 24 h. The culture medium was collected and further prepared for the protein sample.(22) Briefly, $20 \mu \mathrm{L}$ of preparedprotein extract from each treatment group was analyzed by SDS-polyacrylamide gel (PAGE) (L3771, Sigma Aldrich) containing $0.1 \%$ gelatin (G1890, Sigma Aldrich). The gels were rinsed using Triton X-100 2.5\% (T8787, Sigma Aldrich), followed by incubation in incubation solution for $24 \mathrm{~h}$ at $37^{\circ} \mathrm{C}$. On the next day, the incubation solution was replaced with Coomassie blue (B7920, Sigma Aldrich) and shaker for $30 \mathrm{~min}$. Then, the gels were destained in $80 \%$ methanol (\#106009, Merck) and 10\% acetic acid (\#100063, Merck) $(1 \mathrm{~h})$. The quantitative analysis of gelatinase activity from the zymography which displayed as clear bands were conducted by ImageJ version 1.51.

\section{Statistical Analysis}

The data presented in this study were demonstrated as the mean of 3 data \pm standard error (SE). We assessed one-way 
analysis with variance (ANOVA) $(p<0.05)$ continued by post hoc Dunnett's test to define the differences between groups by using IBM SPSS Statistic Ver. 25 (IBM Corporation, Armonk, NY, USA).

\section{Results}

\section{The Expression of MMP9 in Colon Cancer}

The MMPs protein, specifically MMP9, carries out the selective proteolytic degradation of extracellular matrix (ECM) to facilitate compulsory steps for cancer cell migration and invasion. Increased MMP expressions generally promote hallmarks of cancer progression, including angiogenesis, invasion, and metastasis, and correlate with shortened patient survival. We generated the UALCAN online database based on TCGA dataset and found that MMP9 expressions were significantly higher in primary tumor compared to normal colon tissue (Figure
2A). Based on nodal metastases status, from no regional nodal spread (N0) to several degrees of nodal spread (N1N2), MMP9 expression was significantly higher than normal colon tissue (Figure 2B). In more detail, MMP9 expression was also higher in both TP53-Mutant and Non-Mutant sample types (Figure 2C). The higher MMP9 expressions were validated in colon tumor tissues than normal tissues using The Human Protein Atlas dataset (Figure 2D). The MMP9 antibody staining by immunohistochemistry was detected in moderate intensity in tumor colon tissue, but not in normal colon tissue.

\section{Survival Analysis to TP53 and MMP9 Expression in the Colon Cancer Patient}

We compared the survival rates of high and low TP53 (wild type) and MMP9 expression since the loss function of TP53 in colon cancer correlated with intricate downstream signaling leads to more aggressive and metastatic cancer cells.(23) The results showed that patients with high
$\mathbf{A}$

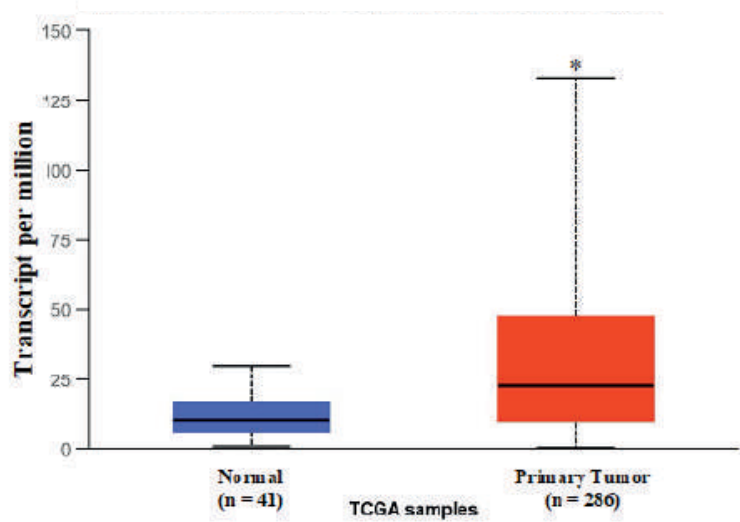

C

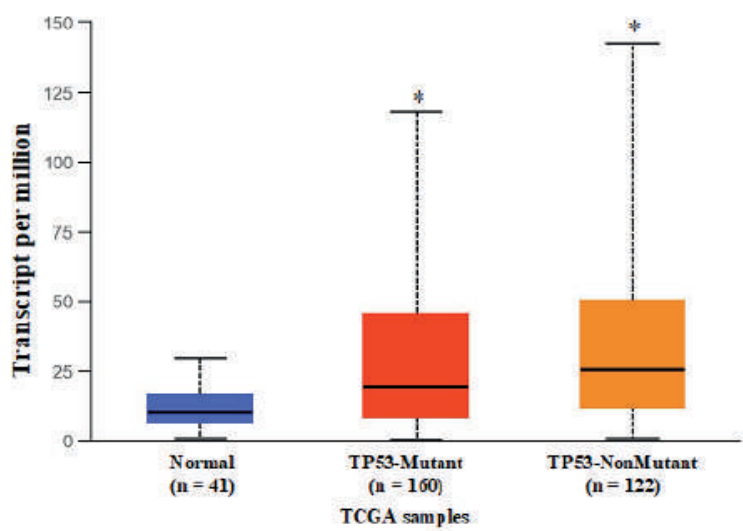

B

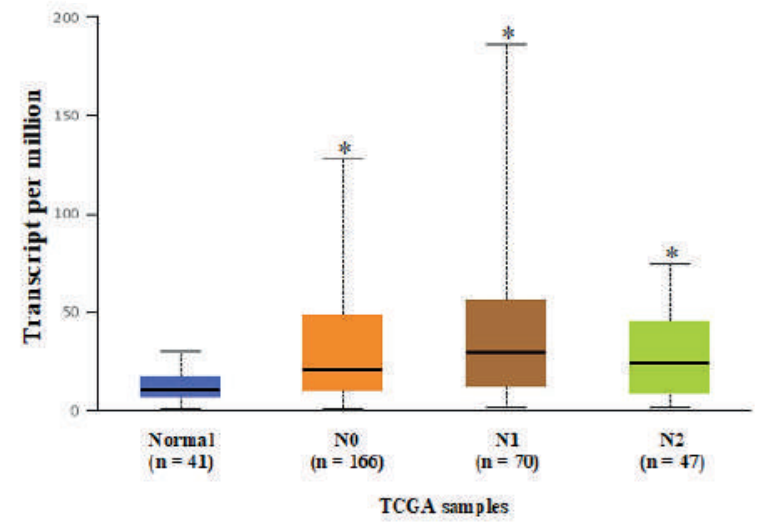

D

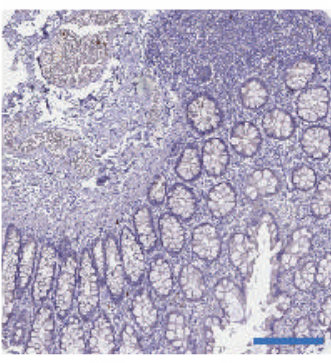

Normal

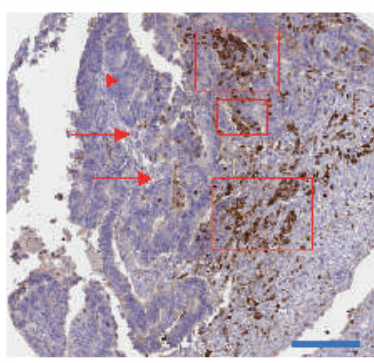

Tumor

Figure 2. The MMP9 expression in colon cancer. A: in normal $(n=41) v s$. primary tumor $(n=286)$; B: metastases nodal $(\mathrm{N} 0 \mathrm{n}=166$; $\mathrm{N} 1$ $n=70$; N2 n=47); C: TP53 mutant (TP53-Mutant $n=160$; TP53-NonMutant $n=122$ ) sample types from UALCAN database; D: the map of MMP immunohistochemistry in the colon tissues from the human protein Atlas dataset (red arrows indicated tumor cells and the red square indicated MMP9 antibody staining was detected (brown color)). Blue bar: $100 \mu \mathrm{m}$. 

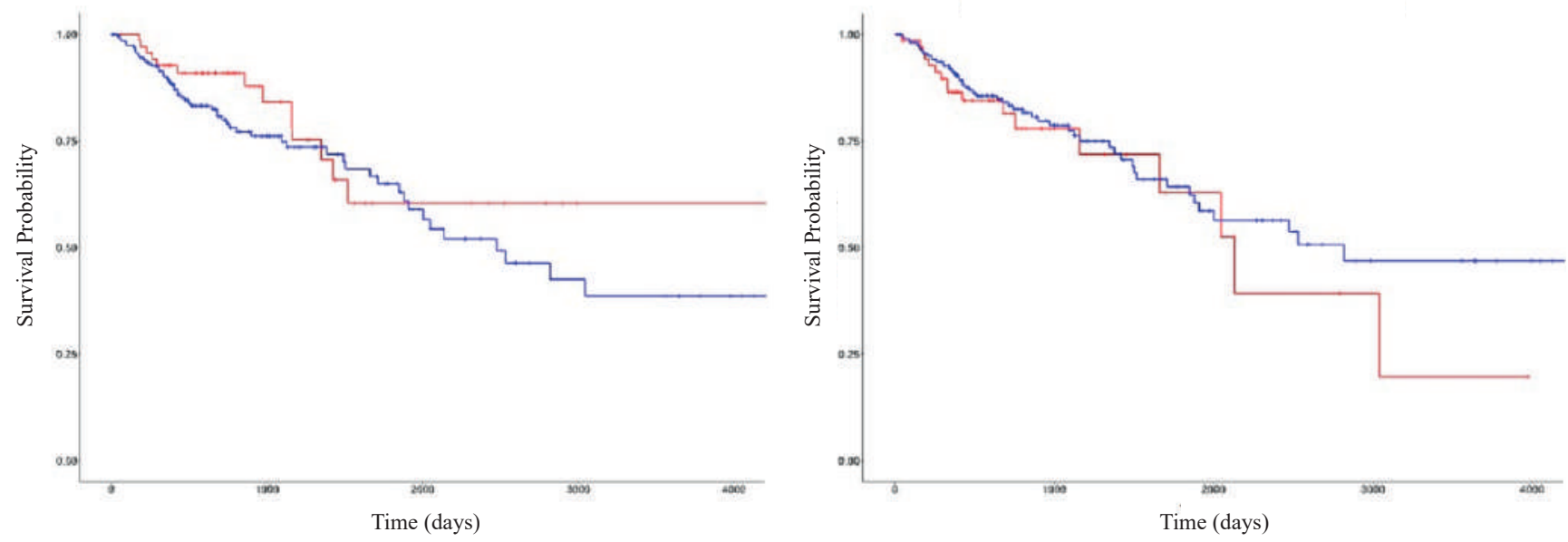

Figure 3. Survival analysis of TP53 and MMP9 genes in colon cancer patients. The red plots present the high expression ( $\mathrm{n}=71)$ of each individual while the blue plots present the median/low expression $(\mathrm{n}=207)$ of each individual $(p<0.05)$.

TP53 expression survival rates were higher than those of patients with a low expression of TP53 protein. Otherwise, the higher expression of MMP9 had significantly shorter overall survival than those with a lower expression with a better prognosis (Figure 3). The expression status of TP53 and MMP9 displayed an opposite pattern and encouraged their correlation in colon cancer progression.

\section{CCA-1.1 Inhibits Growth of WiDr Colon Cancer Cells}

We checked over the cytotoxic potency from CCA-1.1 against WiDr colon cancer cells. The $\mathrm{IC}_{50}$ of CCA-1.1 and PGV-1 after $24 \mathrm{~h}$ of treatment obtained from the linear regression analysis were 5 and $12 \mu \mathrm{M}$, respectively (Figure 4). The prolonged incubation up to $48 \mathrm{~h}$ of treatment resulted in the $\mathrm{IC}_{50}$ values of 0.5 and $1 \mu \mathrm{M}$, respectively, for CCA1.1 and PGV-1.

\section{CCA-1.1 Inhibits Cells Migration of WiDr Colon Cancer Cells}

We then conducted the scratch wound healing assay in WiDr cells to evaluate the potential inhibitory effect in colon cancer's metastatic progression. CCA-1.1 exhibited an anti-migratory effect at doses as low as 0.5 and $1 \mu \mathrm{M}$, more potent than PGV-1 (Figure 5). The combination of CCA-1.1 and PGV-1 with Dox (as positive control) resulted in a lower percentage of closure compared with single Dox, indicating that CCA-1.1 and PGV-1 have potency as an antimigratory agent in metastasis-induced colon cancer.

\section{CCA-1.1 Decreases the Expression Level of MMP9 on WiDr Cancer Cells}

As the next step of CCA-1.1's anti-migratory exploration, we observe the expression of MMP9 proteins, which implicates

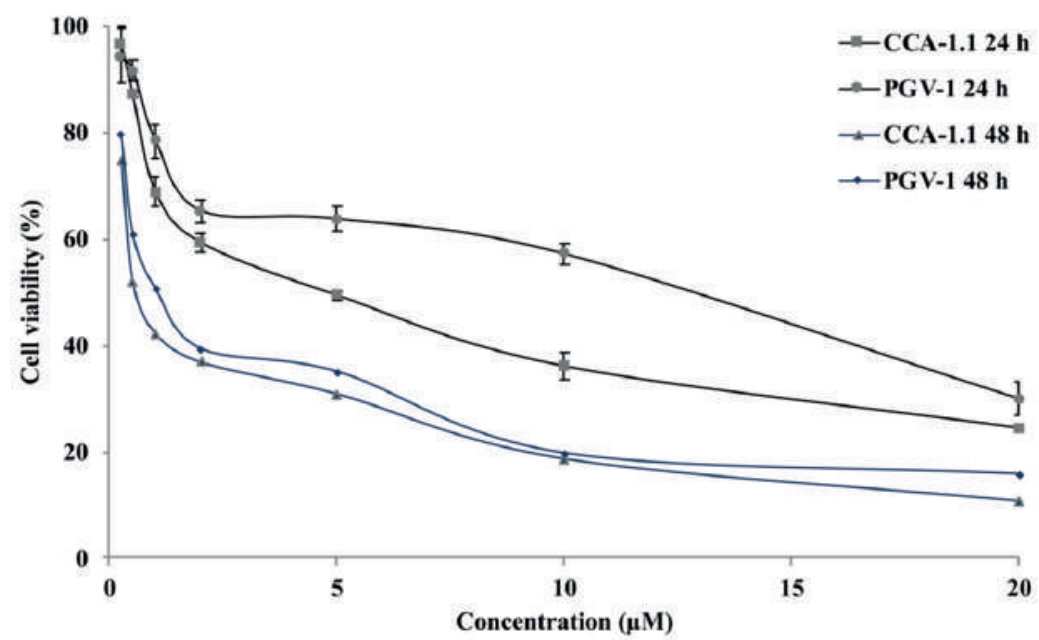

\begin{tabular}{|c|c|c|}
\hline & $24 \mathrm{~h}$ & $48 \mathrm{~h}$ \\
\hline CCA-1.1 & $5 \mu \mathrm{M}$ & $0.5 \mu \mathrm{M}$ \\
\hline PGV-1 & $12 \mu \mathrm{M}$ & $1 \mu \mathrm{M}$ \\
\hline
\end{tabular}

Figure 4. Cytotoxic effects from CCA-1.1 and PGV-1 on WiDr cells in 24 and $\mathbf{4 8}$ h treatment. Cells were grown overnight in 96-well plates and treated with CCA-1.1 or PGV-1. The cell viability was evaluated using MTT assay as mentioned in the method section. The data is presented as the mean $\pm \mathrm{SE}$ from three replications. 

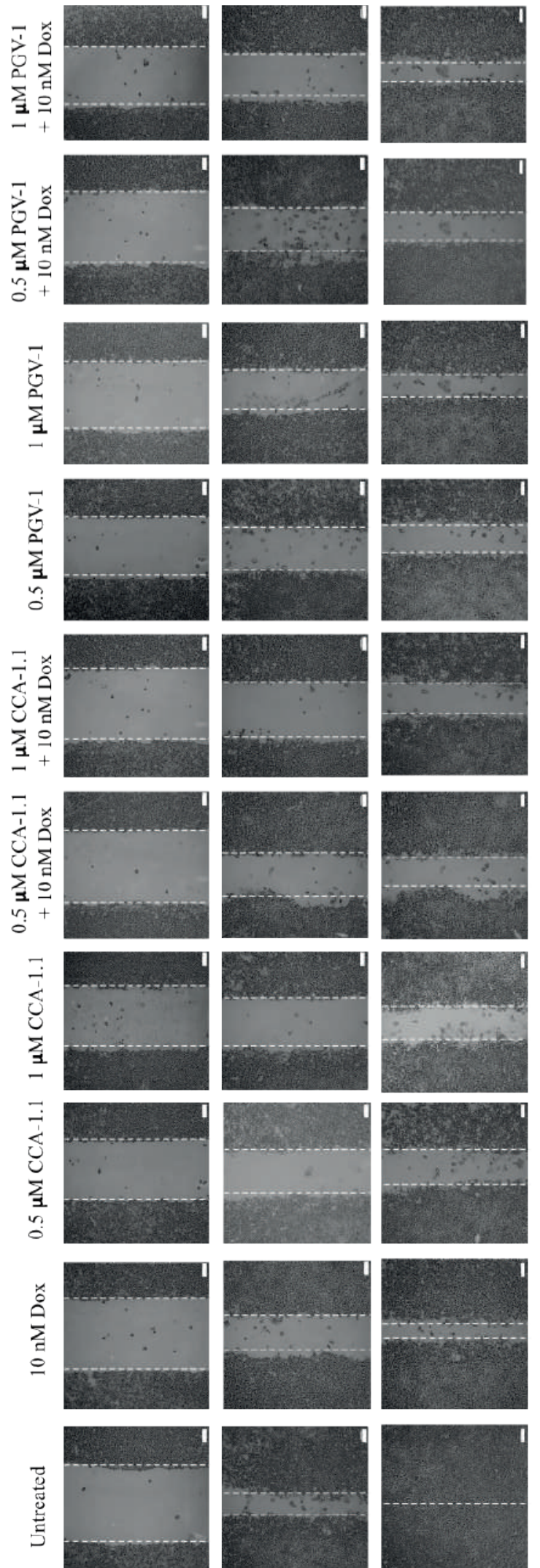

5

咅
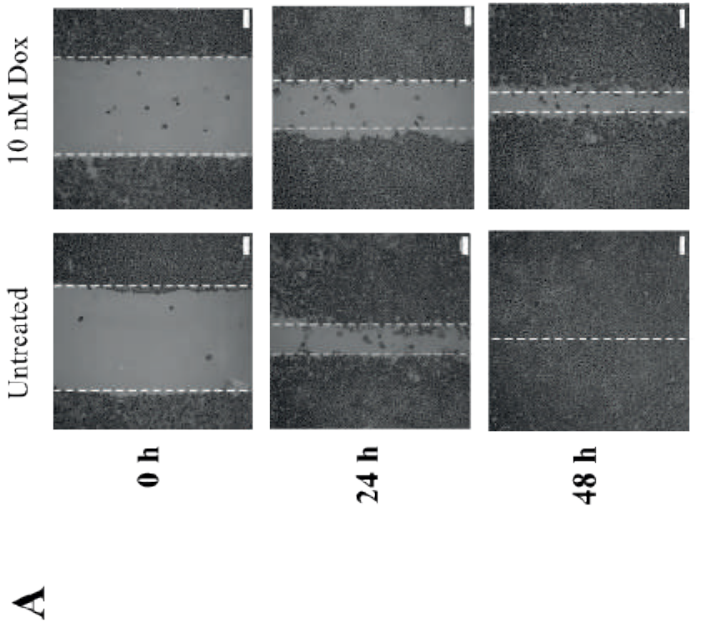

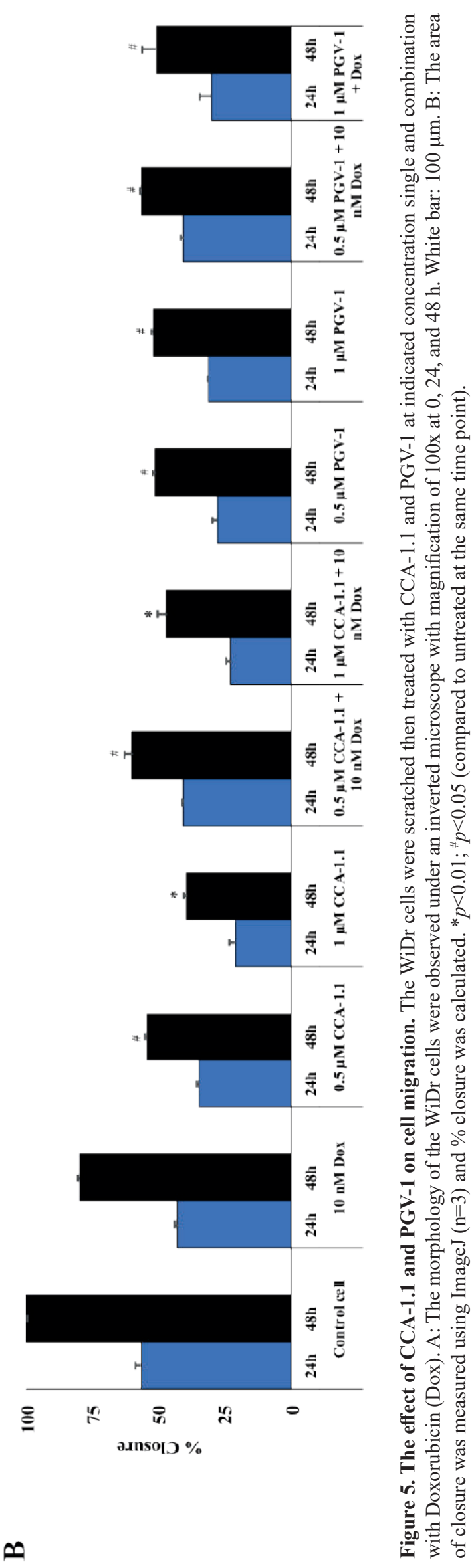


evidently in the metastasis cascade, including cancer cell migration and invasion. Matrix metalloproteinase proteins, especially MMP9, mediates pro-inflammatory and degrades extracellular matrix components, enabling cancer cells to infect their adjacent cells and tissues. We tested the effect of CCA-1.1 in MMP9 expression using gelatin zymography (Figure 6). We found that CCA-1.1 suppressed the expression of MMP9 significantly at the low dose as $0.5 \mu \mathrm{M}$ in WiDr cells. We also found that PGV-1 also suppressed MMP9 expression, but CCA-1.1 exhibited significantly stronger than that of PGV-1 inhibitory effect.

\section{Discussion}

This study evaluated the anti-migratory effect of CCA-1.1 and PGV-1 against colon cancer characterized by metastatic subtype.(11) In this regard, we focus on the main player and phenomenon related to the metastasis evidence, namely cell migration and MMP9 expression (24), by exploring cancer databases and in vitro experiments using the WiDr cell line as a metastatic colon cancer model. We confirmed that MMP9 expression was found to be significantly higher in the primary tumor, metastasis nodal, and tumor with or without TP53 mutation, also significantly influence in survival estimation of colon cancer patients. It is interesting since most aggressive and metastatic colon cancer cells, such as WiDr, were featured by TP53 mutation (23) and closely associated with nuclear factor $-\kappa \mathrm{B}(\mathrm{NF}-\kappa \mathrm{B})$ through tumor necrosis factor- $\alpha$ (TNF- $\alpha$ ) dependent induction signaling pathway (25), which also plays a role as a central manager in almost cancer progression (26). These data give thorough comprehensions about MMP9 and TP53-mutant which are mutually correlated (Figure 7) (27) and important in colon cancer patients.

Our data demonstrated that CCA-1.1 exhibited a more potent cytotoxic, MMP9 expression and cell migration effect than PGV-1 in WiDr. This study noted additional information to our previous finding that PGV-1 inhibits NF- $\kappa \mathrm{B}$ activation (16) which in turn suppresses MMP9

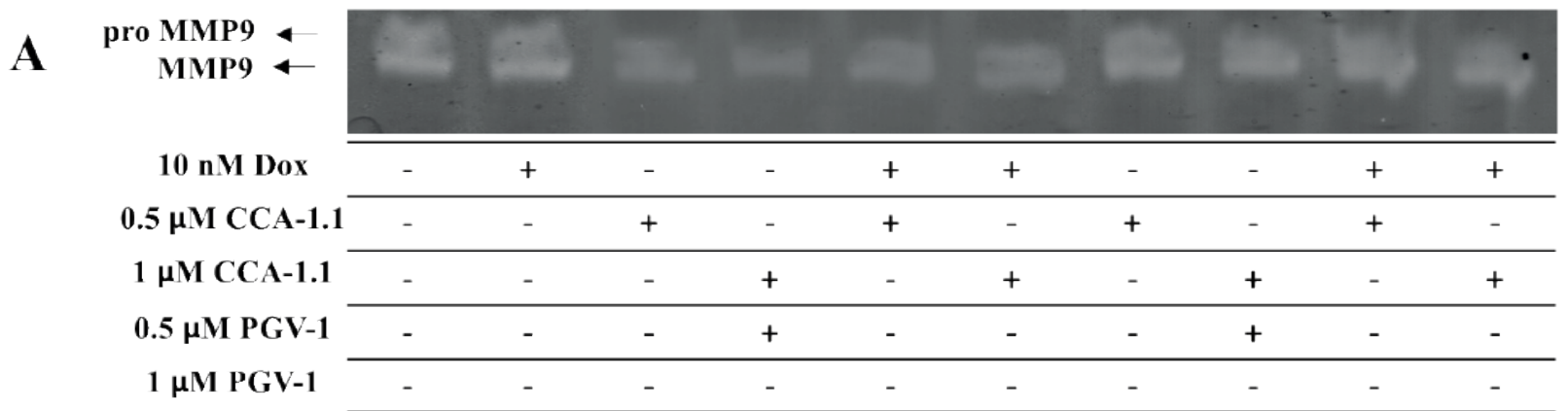

\section{B}

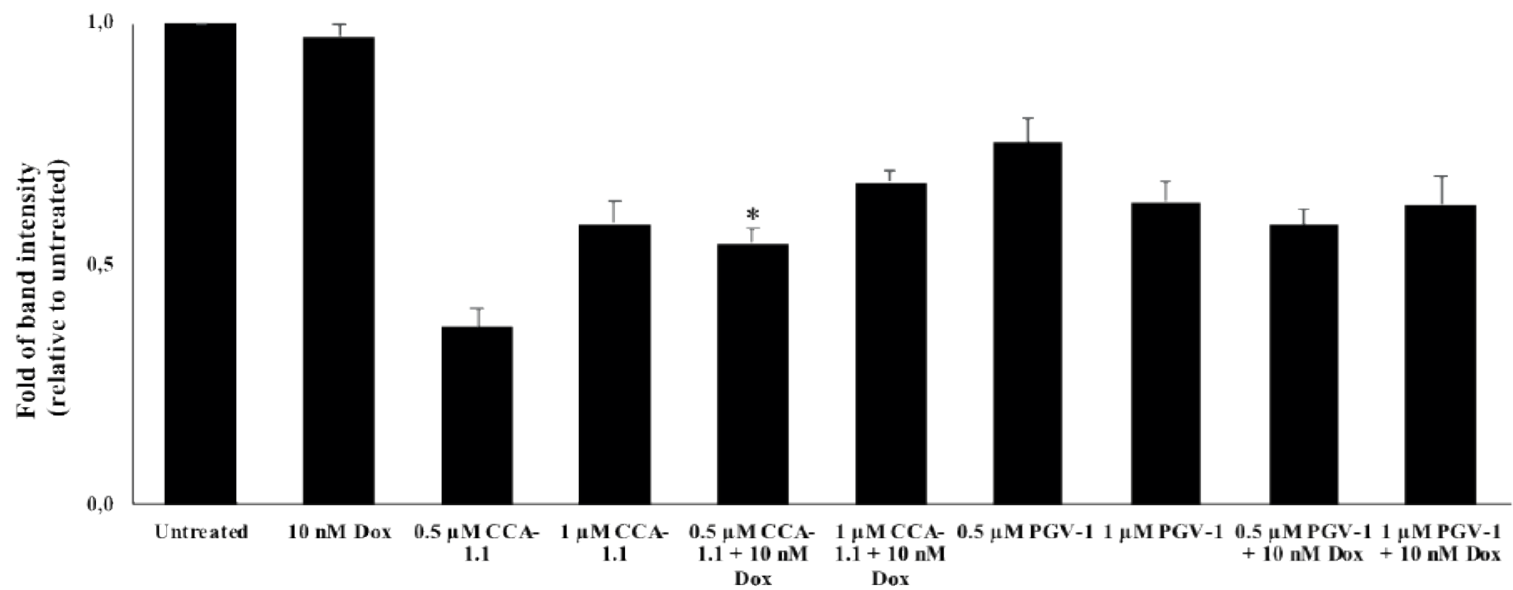

Figure 6. The secretion of MMP9 after CCA-1.1 and PGV-1 treatment. A: The WiDr cells were treated with CCA-1.1 and PGV-1 in single and combination with Doxorubicin (Dox) at the indicated concentration for $24 \mathrm{~h}$. The band profiles of MMP9 and pro MMP9 expression in WiDr cells. B: A graph of quantified band intensity using ImageJ. ${ }^{*} p<0.01$ (compared to untreated). 

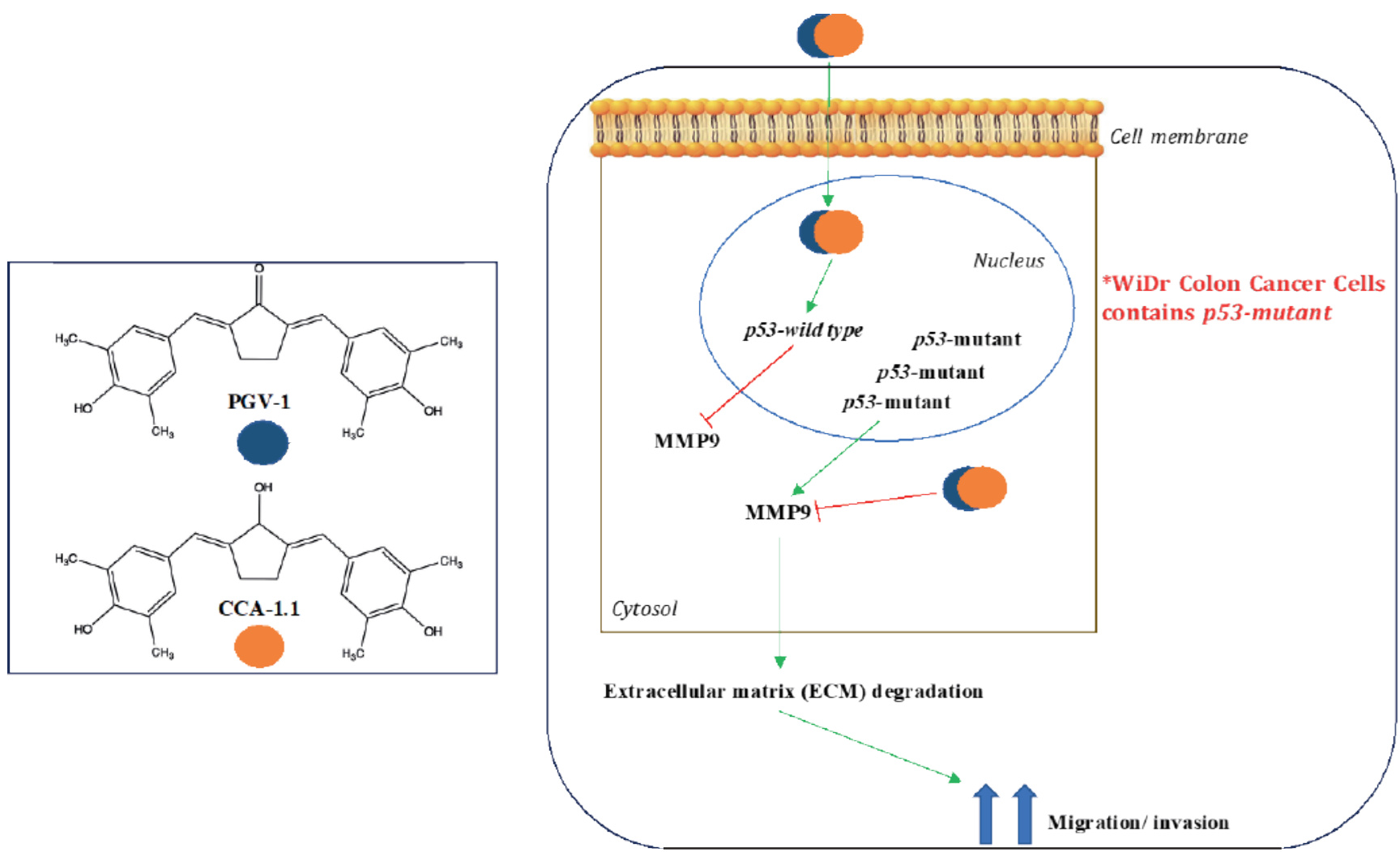

Figure 7. The proposed anti-migration mechanism of CCA-1.1 and PGV-1 in WiDr colon cancer cells.

expression (28). Furthermore, we demonstrated that a single treatment of CCA-1.1 was more potent to inhibit MMP9 expression than PGV-1. This finding allows us to speculate whether CCA-1.1 also targets the NF- $\kappa \mathrm{B}$ activation as well as PGV-1.(16) At least, we found an exciting result of the superiority of CCA-1.1 against PGV-1 on WiDr cells. This will be an interesting challenge for further development as anti-colon cancer with metastatic characteristics.

In more depth, CCA-1.1 and PGV-1 showed to inhibit cancer migration in doxorubicin-induced metastatic WiDr cells. Even though Dox is not included in the drug of choice for colon cancer (29), we suppose employing Dox as a ROS-inducing agent is highly related to the induction of cell migration and MMP9 expression (17). Ten nM Dox was also reported to induced lamellipodia formation that facilitates cancer migration and invasion (30), promotes Dox suitable as a positive control in this study. However, we realized that Dox treatment slightly inhibits cell migration and MMP9 expression on WiDr. This phenomenon suggests that Dox induced-cell migration and MMP9 expression may depend on cancer cell type.(30-32) Interestingly, the Dox combination with CCA-1.1 or PGV-1 could significantly inhibit cancer migration and MMP9 expression compared with single Dox by which CCA-1.1 looks to be superior to PGV-1. Whether these effects correlate to the inhibition of ROS metabolic pathways should be explored further.

The better achievement of CCA-1.1 in anti-migratory effects than PGV-1 is an intriguing point to discuss further. The slight structural changes of PGV-1 to CCA-1.1 by modifying the cyclic ketone into cyclic alcohol might affect its anti-cancer activity, not only its chemical properties. In addition, the presence of a hydroxyl group replacing the ketone group allows CCA-1.1 to be less reactive to radical attack (33) and easily reacted with polar compounds, such as a peptide and polyhydroxy carbon to further derivatized to improve its solubility and bioavailability for therapeutic purposes $(34,35)$. Molecular docking studies of CCA1.1 highlighted the contribution of hydroxyl group on the formation of hydrophobic or hydrogen bond to increase the affinity on several cancer marker proteins, including MMP2 and MMP9.(4) By looking at NF-кB's involvement, CCA1.1 could bind to this protein in better affinity than PGV-1, possibly due to the hydroxyl group's presence in the cyclic structure (Figure 1), which contributes to form hydrogen bonds with NF-kB. This is a unique fact that ligand binding affinity could be strengthened by only one hydrogen atom 
replenishment, resolving the complexity of bulk solvent and protein-bound water molecules.(36) In the case of CCA1.1 capable of improved protein-binding affinity better than PGV-1, it should be more investigated.

This study can be used as a basis for deeper exploration of CCA-1.1 and PGV-1 to be developed as an anti-metastasis-colon cancer candidate related to the inhibition of cancer migration and MMP9 expression (Figure 7). The use of doxorubicin in this experiment grants further insight that CCA-1.1 and PGV-1 have a preferred safety than conventional chemotherapeutic agents for clinical application.(37) Dox is a relatively affordable chemotherapeutic drug, but is not a recommended choice for colon cancer therapy because the difficulties to avoid the side effects and its resistance problems, also the stability problems for oral use.(29) However, there are many studies to optimize Dox for colon cancer treatment using some complementary agent to overcome problems caused by Dox.(29)

We displayed the possibility of CCA-1.1 and PGV1 to overcome the side effect of Dox, counteract cancer migration caused by excessive ROS formation.(38) PGV1 itself was confirmed to be less toxic in non-cancerous fibroblast cells with high selectivity in cancer cells.(38) We figure out CCA-1.1 would be mirroring the selectivity of PGV-1. It needs to be elucidated further to know our compound's selectivity, especially CCA-1.1, in normal cells to confirm the drug safety aspect for future purposes.

\section{Conclusion}

Our results suggest that MMP9 is the essential marker of colon cancer, especially cancer with TP53 mutation, that can be the drug-target in developing anti-metastasis agents to cure colon cancer metastasis. We conclude that PGV-1 and CCA-1.1 showed cytotoxic, MMP9 expression, and cell migration inhibitory activities against WiDr cells in which CCA-1.1 shows better performance than PGV-1. Therefore, CCA-1.1 can be the better choice to be developed as antimetastasis agents for colon cancers.

\section{Acknowledgements}

This study is financially supported by Master Education Leading to Doctoral Program for Excellent Graduate (PMDSU) Research Scheme.

\section{Authors Contribution}

FW, MI, MK, JK, and EM were involved in the conception and planning of the research; FW performed the data acquisition/collection; FW, MI, and EM calculated the experimental data and performed the analysis; all authors contributed to the manuscript drafting; FW was designed the figures; and MI and EM were supervising in interpreting the results. All authors took part in giving critical revision of the manuscript.

\section{References}

1. Novitasari D, Wulandari F, Jenie RI, Utomo RY, Kato JY, Meiyanto E. A new curcumin analog, CCA-1.1, induces cell cycle arrest and senescence toward ER-positive breast cancer cells. Int J Pharm Sci Res. 2021; 13: 9. doi: 10.31838/ijpr/2021.13.01.002.

2. Novitasari D, Jenie RI, Wulandari F, Utomo RY, Putri DDP, Kato JY, et al. A curcumin like structure (CCA-1.1) induces permanent mitotic arrest (senescence) on triple negative breast cancer (TNBC) cells, 4T1. Res J Pharm Sci. 2021; in press.

3. Wulandari F, Ikawati M, Meiyanto E, Kirihata M, Hermawan A. Bioinformatic analysis of CCA-1.1, a novel curcumin analog, uncovers furthermost noticeable target genes in colon cancer. Gene Rep. 2020; 21: 100917.

4. Wulandari F, Utomo RY, Novitasari D, Ikawati M, Kirihata M, Kato JY, et al. The anti-migratory activity of a new curcumin analog, CCA-1.1, against T47D breast cancer cells. Int J Pharm Sci Res. 2021; 13: 2877-87.

5. Nguyen H, Duong H. The molecular characteristics of colorectal cancer: Implications for diagnosis and therapy (Review). Oncol Lett. 2018; 16: 9-18.

6. García-Aranda M, Redondo M. Targeting receptor kinases in colorectal cancer. Cancers. 2019; 11: 433. doi: 10.3390/cancers 11040433.

7. Solé X, Crous-Bou M, Cordero D, Olivares D, Guinó E, SanzPamplona R, et al. Discovery and validation of new potential biomarkers for early detection of colon cancer. PLoS ONE. 2014; 9: e106748. doi: 10.3390/cancers11040433.

8. De Angelis PM, Svendsrud DH, Kravik KL, Stokke T. Cellular response to 5-fluorouracil (5-FU) in 5-FU-resistant colon cancer cell lines during treatment and recovery. Mol Cancer. 2006; 5: 20 . doi: 10.1186/1476-4598-5-20.

9. Jin J, Wu X, Yin J, Li M, Shen J, Li J, et al. Identification of genetic mutations in cancer: challenge and opportunity in the new era of targeted therapy. Front Oncol. 2019; 9: 263. doi: 10.3389/ fonc. 2019.00263 .

10. Li H, Zhang J, Tong JHM, Chan AWH, Yu J, Kang W, et al. Targeting the oncogenic p53 mutants in colorectal cancer and other solid tumors. IJMS. 2019; 20: 5999. doi: 10.3390/ijms20235999.

11. Noguchi P, Wallace R, Johnson J, Earley EM, O’Brien S, Ferrone S, et al. Characterization of WiDr: a human colon carcinoma cell line. In Vitro. 1979; 15: 401-8.

12. Said A, Raufman JP, Xie G. The role of matrix metalloproteinases in colorectal cancer. Cancers. 2014; 6: 366-75. 
13. Utami DT, Nugraheni N, Jenie RI, Meiyanto E. Co-treatment of brazilein enhances cytotoxicity of doxorubicin on WiDr colorectal cancer cells through cell cycle arrest. Indones Biomed J. 2020; 12: 376-83.

14. Pretzsch E, Bösch F, Neumann J, Ganschow P, Bazhin A, Guba M, et al. Mechanisms of metastasis in colorectal cancer and metastatic organotropism: hematogenous versus peritoneal spread. J Oncol. 2019; 2019: 7407190. doi: 10.1155/2019/7407190.

15. Oden-Gangloff A, Di Fiore F, Bibeau F, Lamy A, Bougeard G, Charbonnier F, et al. TP53 mutations predict disease control in metastatic colorectal cancer treated with cetuximab-based chemotherapy. Br J Cancer. 2009; 100: 1330-5.

16. Meiyanto E, Septisetyani EP, Larasati YA, Kawaichi M. Curcumin analog pentagamavunon-1 (PGV-1) sensitizes Widr cells to 5-fluorouracil through inhibition of NF-kB activation. Asian Pac J Cancer Prev. 2018; 19: 49-56.

17. Meiyanto E, Putri H, Larasati YA, Utomo RY, Jenie RI, Ikawati M, et al. Anti-proliferative and anti-metastatic potential of curcumin analogue, pentagamavunon-1 (PGV-1), toward highly metastatic breast cancer cells in correlation with ROS generation. Adv Pharm Bull. 2019; 9: 445-52.

18. Meiyanto E, Husnaa U, Kastian RF, Putri H, Larasati1 YA, Khumaira $\mathrm{A}$, et al. The target differences of anti-tumorigenesis potential of curcumin and its analogues against HER-2 positive and triplenegative breast cancer cells. Adv Pharm Bull. 2021; 11:188-96.

19. Chandrashekar DS, Bashel B, Balasubramanya SAH, Creighton CJ, Ponce-Rodriguez I, Chakravarthi BVSK, et al. UALCAN: a portal for facilitating tumor subgroup gene expression and survival analyses. Neoplasia. 2017; 19: 649-58.

20. Utomo RY, Wulandari F, Novitasari D, Lestari B, Susidarti RA, Jenie RI, et al. Preparation and cytotoxic evaluation of PGV-1 derivative, CCA-1.1, as a new curcumin analog with improvedphysicochemical and pharmacological properties. Adv Pharm Bull. 2021; in press.

21. Mosmann T. Rapid colorimetric assay for cellular growth and survival: application to proliferation and cytotoxicity assays. J Immunol Methods. 1983; 65: 55-63.

22. Ahlina FN, Nugraheni N, Salsabila IA, Haryanti S, Da'i M, Meiyanto E. Revealing the reversal effect of galangal (Alpinia galanga L.) extract against oxidative stress in metastatic breast cancer cells and normal fibroblast cells intended as a co-chemotherapeutic and antiageing agent. Asian Pac J Cancer Prev. 2020; 21: 107-17.

23. Nakayama M, Oshima M. Mutant p53 in colon cancer. J Mol Cell Biol. 2019; 11: 267-76.

24. Guntarno NC, Rahaju AS, Kurniasari N. The role of MMP-9 and VEGF in the invasion state of bladder urothelial carcinoma. Indones Biomed J. 2021; 13: 61-7.
25. Meteoglu I, Erdogdu IH, Tuncyurek P, Coskun A, Culhaci N, Erkus $\mathrm{M}$, et al. Nuclear factor kappa B, matrix metalloproteinase-1, p53, and Ki-67 expressions in the primary tumors and the lymph node metastases of colorectal cancer cases. Gastroenterol Res Pract. 2015; 2015: 945392. doi: 10.1155/2015/945392.

26. Blaj C, Schmidt EM, Lamprecht S, Hermeking H, Jung A, Kirchner T, et al. Oncogenic effects of high MAPK activity in colorectal cancer mark progenitor cells and persist irrespective of RAS mutations. Cancer Res. 2017; 77: 1763-74.

27. Cohen M, Wuillemin C, Irion O, Bischof P. Regulation of MMP-9 by p53 in first trimester cytotrophoblastic cells. Hum Reprod. 2008; 23: $2273-81$.

28. Zhang S, Wu M, Zhao Y, Gu R, Peng C, Liu J, et al. Correlation of MMP-9 and $\mathrm{p} 53$ protein expression with prognosis in metastatic spinal tumor of lung cancer. Oncol Lett. 2017; 14: 5452-6.

29. Xiong S, Xiao GW. Reverting doxorubicin resistance in colon cancer by targeting a key signaling protein, steroid receptor coactivator. Exp Ther Med. 2018; 15: 3751-8.

30. Amalina N, Nurhayati IP, Meiyanto E. Doxorubicin induces lamellipodia formation and cell migration. Indones $\mathrm{J}$ Cancer Chemoprev. 2017; 8: 61-7.

31. Huang H. Matrix metalloproteinase-9 (MMP-9) as a cancer biomarker and MMP-9 biosensors: recent advances. Sensors. 2018; 18: 3249. doi: $10.3390 / \mathrm{s} 18103249$.

32. Justus CR, Leffler N, Ruiz-Echevarria M, Yang LV. In vitro cell migration and invasion assays. J Vis Exp. 2014; 88: 51046. doi: 10.3791/51046.

33. Burgos-Morón E, Calderón-Montaño JM, Salvador J, Robles A, López-Lázaro M. The dark side of curcumin. Int J Cancer. 2010; 126: $1771-5$.

34. Aravind SR, Krishnan LK. Curcumin-albumin conjugates as an effective anti-cancer agent with immunomodulatory properties. Int Immunopharmacol. 2016; 34: 78-85.

35. Darwish S, Mozaffari S, Parang K, Tiwari R. Cyclic peptide conjugate of curcumin and doxorubicin as an anticancer agent. Tetrahedron Letters. 2017; 58: 4617-22.

36. Chen D, Oezguen N, Urvil P, Ferguson C, Dann SM, Savidge TC. Regulation of protein-ligand binding affinity by hydrogen bond pairing. Sci Adv. 2016; 2: e1501240. doi: 10.1126/sciadv.1501240.

37. Tan BL, Norhaizan ME. Curcumin combination chemotherapy: the implication and efficacy in cancer. Molecules. 2019; 24: 2527. doi: 10.3390/molecules24142527.

38. Lestari B, Nakamae I, Yoneda-Kato N, Morimoto T, Kanaya S, Yokoyama T, et al. Pentagamavunon-1 (PGV-1) inhibits ROS metabolic enzymes and suppresses tumor cell growth by inducing M phase (prometaphase) arrest and cell senescence. Sci Rep. 2019; 9: 14867. doi: 10.1038/s41598-019-51244-3. 